\title{
Spontaneous Assembly of Exopolymers from Phytoplankton
}

\author{
Yong-Xue Ding ${ }^{1,2}$, Chin-Chang Hung ${ }^{3}$, Peter H. Santschi ${ }^{4}$, \\ Pedro Verdugo ${ }^{5}$, and Wei-Chun Chin ${ }^{6, *}$ \\ ${ }^{1}$ Friday Harbor Laboratories, University of Washington, Friday Harbor, WA 98250, USA \\ ${ }^{2}$ Department of Bioengineering, University of Utah, Salt Lake City, UT 84112, USA \\ ${ }^{3}$ Institute of Marine Environmental Chemistry and Ecology, National Taiwan Ocean University, Keelung 20224, Taiwan, ROC \\ ${ }^{4}$ Laboratory for Oceanographic and Environmental Research, Department of Marine Sciences and Oceanography, \\ Texas A\&M University, Galveston, TX 77551, USA \\ ${ }^{5}$ Department of Bioengineering and Friday Harbor Laboratories, University of Washington, Friday Harbor, WA 98250, USA \\ ${ }^{6}$ School of Engineering, University of California, Merced, CA 95344, USA
}

Received 17 May 2008, accepted 26 August 2008

\begin{abstract}
Phytoplankton exopolymeric substances (EPS) contribute significantly to the dissolved organic carbon (DOC) pool in the ocean, playing crucial roles in the surface ocean carbon cycle. Recent studies have demonstrated that $10 \%$ of marine DOC can self-assemble as microgels through electrostatic Ca bonds providing hotspots of enriched microbial substrate. However, the question whether EPS can self-assemble and the formation mechanisms for EPS microgels have not been examined. Here we report that EPS from three representative phytoplankton species, Synechococcus, Emiliania huxleyi, and Skeletonema costatum can spontaneously self assemble in artificial seawater (ASW), forming microscopic gels of $\sim 3-4 \mu \mathrm{m}$ in diameter. Different from the marine DOC polymers assembly, these EPS samples can self-assemble in $\mathrm{Ca}^{2+}$-free ASW. Further experiments from fluorescence enhancement and chemical composition analysis confirmed the existence of fair amounts of hydrophobic domains in these EPS samples. These results suggest that hydrophobic interactions play a key role in the assembly of EPS from these three species of marine phytoplankton.
\end{abstract}

Key words: Phytoplankton, Exopolymeric subatances (EPS), Microgel, Assembly

Citation: Ding, Y. X., C. C. Hung, P. H. Santschi, P. Verdugo, and W. C. Chin, 2009: Spontaneous assembly of exopolymers from phytoplankton. Terr. Atmos. Ocean. Sci., 20, 741-747, doi: 10.3319/TAO.2008.08.26.01(Oc)

\section{INTRODUCTION}

About half of the global photosynthetic activity takes place in the ocean (Chisholm 2000). Phytoplankton in surface seawater is a major driving force in sequestering greenhouse gas $\mathrm{CO}_{2}$ (Falkowski et al. 2000; Chisholm 2000). A significant portion of photosynthetic production in phytoplankton is released as exopolymeric substances (EPS) into the dissolved organic carbon (DOC) pool (Fogg 1983; Baines and Pace 1991) contributing to the primary marine carbon reservoir. DOC is largely refractory with turn-over times that can reach up to 6000 years (Williams and Druffel 1987; Hedges 1992; Hedges and Oades 1997). The recent discovery that $\sim 10 \%$ of the DOC pool can self-assemble forming porous microscopic gels that can be readily colo-

\footnotetext{
* Corresponding author

E-mail:wchin2@ucmerced.edu
}

nized and metabolized by marine bacteria opens a new pathway for DOC and carbon cycling in the oceans (Chin et al. 1998; Wells 1998; Orellana et al. 2000; Verdugo et al. 2004; Ding et al. 2008; Verdugo et al. 2008). Since EPS is a major source of both the marine DOC and particulate organic carbon (POC) (Fog 1983; Baines and Pace 1991; Hedges and Oades 1997; Wotton 2004), the verification of whether EPS can self-assemble and to understand the mechanisms how EPS microgels are formed are crititcally important. The complexity of the compositions and the diversity of phytoplankton EPS establish a significant need to verify if these free polymers can self assemble and to investigate the mechanisms responsible for their crosslinking. EPS released by Synechococcus, Emiliania huxleyi, and Skeletonema costatum provide a convenient model to study self-assembly since their chemical features have been re- 
cently reported (Hung et al. 2005; Alvarado Quiroz et al. 2006).

Emiliania huxleyi is the most abundant of the coccolithophores and is exceptionally widespread except in the polar oceans. It can grow in massive blooms when water conditions are favorable. During these blooms the numbers of Emiliania huxleyi cells are higher than all other species combined, frequently accounting for $80-90 \%$ or more of the total number of phytoplankton cells in the water column (Delille 2003). Skeletonema costatum cells usually live in rod-like aggregates, which are connected by numerous tiny spines to form long-chains, normally containing two pigment bodies, with a nucleus at the centre of each cell. This diatom specie is commonly found in most parts of the ocean and is abundant in many temperate oceans. Skeletonema costatum is also an abundant phytoplankton species during coastal eutrophication. The marine unicellular Synechococcus group plays an important role as the base of the marine food chain (Drebes 1974; Medlin et al. 1991). Synechococcus species have the ability to acquire major nutrients and trace metals from the submicromolar concentrations found in the oligotrophic open oceans and their light-harvesting apparatus is uniquely adapted to the spectral distribution of light in the ocean. Synechococcus species are the main source of primary production in oligotrophic, pelagic marine waters. They can also cause destructive blooms producing neurotoxins (Campbell et al. 1998; Zouni et al. 2001).

In this study, particle sizing by dynamic laser scattering (DLS) was used to monitor the assembly process of EPS. Hydrophobic dye, Nile red, was applied to demonstrate the existence of hydrophobic domains. Here we investigated the relative role of electrostatic and hydrophobic intractions in EPS self-assembly.

\section{EXPERIMENTAL METHODS}

\subsection{Chemicals}

Nile red was used as a hydrophobic indicator (Molecular Probes, Eugene, OR, USA). EGTA (glycol-bis(2aminoethylether)-N,N, $\mathrm{N}^{\prime}, \mathrm{N}^{\prime}$-tetraacetic acid) from SigmaAldrich (St. Lious, Mo, USA) was used to chelate $\mathrm{Ca}^{2+}$ in artificial seawater (ASW). ASW (423 mM NaCl, $9 \mathrm{mM} \mathrm{KCl,}$ $9.27 \mathrm{mM} \mathrm{CaCl}_{2}, 22.94 \mathrm{mM} \mathrm{MgCl}_{2}, 25.5 \mathrm{mM} \mathrm{MgSO}_{4}$, and $2.14 \mathrm{mM} \mathrm{NaHCO}_{3}$ ) and $\mathrm{Ca}^{2+}$-free ASW $(436.71 \mathrm{mM} \mathrm{NaCl}$, $9 \mathrm{mM} \mathrm{KCl}, 22.94 \mathrm{mM} \mathrm{MgCl} 2,25.5 \mathrm{mM} \mathrm{MgSO}_{4}, 2.14 \mathrm{mM}$ $\mathrm{NaHCO}_{3}$, and $1 \mathrm{mM} \mathrm{EGTA}$ ) were prepared using de-ionized water from a Milli-Q system (Millipore, MA, USA) following established protocols from Marine Biological Laboratory, Woods Hole, MA (http://www.mbl.edu/BiologicalBulletin/COMPENDIUM/CompTab3.html). EGTA was used here due to its better selective binding for $\mathrm{Ca}^{2+}$ than commonly used EDTA (ethylenediamine-tetra-acetic acid) (Blanchard 1984; Hamel et al. 1998). HPLC grade reagents and salts including sodium chloride, potassium chloride, calcium chloride, magnesium chloride, magnesium sulfate, and sodium bicarbonate were purchased from Sigma-Aldrich (St. Lious, Mo, USA).

\subsection{Separation and Purification of Phytoplankton EPS}

Cultures of Synechococcus elongatus (CCMP1379), Emiliania huxleyi (CCMP 374), and Skeletonema costatum (CCMP2092) were purchased from the Provasoli-Guillard National Center for Culture of Marine Phytoplankton (West Boothbay Harbor, Maine) and used to generate EPS isolated from the dissolved fraction using an ethanol precipitation procedure (Kushner et al. 1992; Hung et al. 2005; Alvarado et al. 2006). These phytoplankton species were cultured in a f $/ 2$ medium at $20^{\circ} \mathrm{C}$ under a $12: 12$ day/night irradiance cycle. The EPS from phytoplankton cultures were sampled for isolation and purification during their exponential phase. The samples were first centrifuged, which resulted in a particulate (capsular) and a dissolved EPS fraction. The sample from the dissolved EPS fraction was isolated by repeated alcohol precipitation from the nutrient medium, followed the procedure of Hung et al. (2005). The final clear solution was dialyzed at $4^{\circ} \mathrm{C}$ for 5 days under sodium azide. After dialysis, the retentate solution was freeze-dried.

\subsection{Characterization of Exopolymers}

Total carbohydrate concentrations in freeze-dried EPS samples were measured by a spectrophotometric method (Myklestad et al. 1997), as modified by Hung et al. (2005). The concentration of protein in the EPS was measured by a method using bicinchoninic acid and colorimetric detection (Smith et al. 1985). Organic carbon was measured by the method used by Guo et al. (1994). The concentration of total uronic acids (URA), i.e., sugars containing carboxylic acids, was analyzed according to Filisetti-Cozzi and Carpita (1991), modified by Hung et al. (2001). Neutral monosaccharides and individual uronic acids were methanolyzed and measured by the GC-MS method of Doco et al. (2001). Hydrophobic Contact Area was determined according to Van Oss (1995) and Schwehr et al. (in preparation).

EPS from all three species contained $2-3 \%$ protein (Table 1), which is sufficient to give these hydrocolloids amphiphilic and emulsifying properties (Dickinson 2003). Accordingly, measurement of hydrophobic contact area (HCA) of EPS solutions from Skeletonema costatum and Synecoccus revealed 6 and $16 \AA^{2}$ molecule $^{-1}$, respectively while EPS that underwent hydrolytic removal of proteins using pronase treatment rendered only $2 \AA^{2}$ molecule $^{-1}$ (Schwehr et al. in preparation). 
Table 1. Chemical composition of EPS from phytoplankton species.

\begin{tabular}{lcccc}
\hline Phytoplankton Species & TCHO/OC $(\%)$ & Protein-C/OC $(\%)$ & URA/OC $(\%)$ & HCA $\left(\AA^{\mathbf{2}}\right.$ molecule $\left.^{-1}\right)$ \\
\hline Synechococcus & 13.2 & 3.1 & 1.4 & 16 \\
Emiliania huxleyi & 48.9 & 2.1 & 7.4 & - \\
Skeletonema costatum & 35.6 & 2.4 & 9.7 & 6 \\
\hline
\end{tabular}

\subsection{Particle Sizing}

EPS assembly was monitored in solutions containing $100 \mu \mathrm{g} \mathrm{L}^{-1} \mathrm{EPS}$ in ASW and $\mathrm{Ca}^{2+}$-free ASW. The size of assembled networks (microgels) was monitored by dynamic laser scattering (DLS) following protocols published elsewhere (Chin et al. 1998). Briefly, samples were shaken, and refiltered through a $0.22-\mu \mathrm{m}$ Millipore membrane (prewashed with $0.1 \mathrm{~N} \mathrm{HCl}$ ) before use. Aliquots were then poured directly into scattering cells. The scattering cells were positioned in the goniometer of a Brookhaven laser spectrometer (Brookhaven Instruments, NY, USA). The polymer assembly was monitored for $8 \sim 10$ days by analyzing the scattering fluctuations detected at a 45 degree scattering angle. The autocorrelation function of the scattering intensity fluctuations was averaged over a 10-min sampling time, using a Brookhaven BI 9000AT autocorrelator. Particle size distribution was calculated by the CONTIN method (Provencher 1982; Chin et al. 1998). Each measurement was taken in triplicate in 10-ml at room temperature. A calibration of the DLS method was conducted using standard suspensions of latex microspheres (Polysciences, PA, USA).

\subsection{Fluorescence Enhancement Measurement}

Nile red is a commonly used hydrophobic fluorescent dye. It is a particularly effective solvatochromic dye containing a rigid aromatic group and an exocyclic diethylamine group. The absorbance and fluorescence emission depends on the physical properties of the surrounding solvent environment. The fluorescence emission is enhanced with hydrophobic environment exposure (Yablon and Schilowitz 2004). Samples of ASW were mixed with $13 \mu \mathrm{M}$ Nile-red in triplicate. Fluorescence of these mixed samples was measured before and after addition of EPS from Emiliania huxleyi, Skeletonema costatum, and Synecoccus. The fluorescence measurements were obtained with a Shimadzu RF-5000U spectrofluorophotometer $\left(\lambda_{\text {excitation }}=588 \mathrm{~nm}\right.$; $\lambda_{\text {emission }}=633 \mathrm{~nm}$ ). Nile red has also been used in our previous study to identify hydrophobic domains in marine baterial EPS samples (Ding et al. 2008).

\subsection{Statistical Analysis}

Data represent means $\pm \mathrm{SD}$. Each experiment was per- formed in triplicate. A Student's t-test analysis was used to determine statistical significance. $p$ values of $<0.05$ were used as standard for statistical significance (GraphPad Prism 4.0, GraphPad Software, Inc. San Diego, CA).

\section{RESULTS AND DISCUSSION}

\subsection{Assembly of EPS from Phytoplankton in ASW}

The spontaneous assembly of $100 \mu \mathrm{g} \mathrm{L}^{-1}$ Emiliania huxleyi EPS solutions in ASW containing $9 \mathrm{mM} \mathrm{Ca}^{2+}$ was monitored by DSL for $6-8$ days. As shown in Fig. 1a, EPS from Emiliania huxleyi self-assemble following first-order kinetics that reached steady-state assembly/dispersion equilibrium in $\sim 42 \mathrm{hrs}$ yielding microgels of $\sim 3.5 \mu \mathrm{m}$. Similar measurement conducted in $100 \mu \mathrm{g} \mathrm{L}^{-1}$ Emiliania huxleyi EPS solutions in Ca-free ASW showed that the EPS can still self-assemble in the absence of $\mathrm{Ca}^{2+}$. However, the equilibrium size of the microgels in $\mathrm{Ca}^{2+}$-free ASW is much smaller, i.e., only $\sim 1.8 \mu \mathrm{m}$ and took a much longer time (140 hrs) to reach equilibrium (Fig. 1a). Compared with DOC where self-assembly is mainly dependent on $\mathrm{Ca}^{2+}$ (Chin et al. 1998), Emiliania huxleyi EPS self-assembly results most likely from both Ca electrostatic bonding and hydrophobic interactions.

The same protocol was used to test the spontaneous assembly of EPS from Skeletonema costatum (Fig. 1b) and Synechococcus (Fig. 1c). Results show that independent of the presence or absence of $\mathrm{Ca}^{2+}$, both types of EPS polymers can self-assemble following almost identical kinetics and reaching similar microgel equilibrium sizes. These outcomes suggest that unlike DOC, self-assembly of Skeletonema costatum (Fig. 1b) and Synechococcus EPS polymers most likely results from hydrophobic rather than electrostatic $\mathrm{Ca}^{2+}$ bonds. Our results indicate that these different EPS could spontaneously assemble in $\mathrm{Ca}^{2+}$-free ASW. Although self-assembly of EPS from Emiliania huxleyi probably relies in both $\mathrm{Ca}^{2+}$ and hydrophobic bonds, EPS from the other two species can readily self-assemble in $\mathrm{Ca}^{2+}$-free ASW. Protein content of EPS is believed to be the primary contributor of hydrophobic domains for phytoplankton due to the existence of hydrophobic amino acids (e.g., tryptophan, leucine, or phenylalanine) (Alvarado et al. 2006). These assembly results (Figs. 1a - c) are consistent with the chemical analysis of EPS from Emiliania huxleyi indicating the lowest protein and the highest carbohydrate content of 


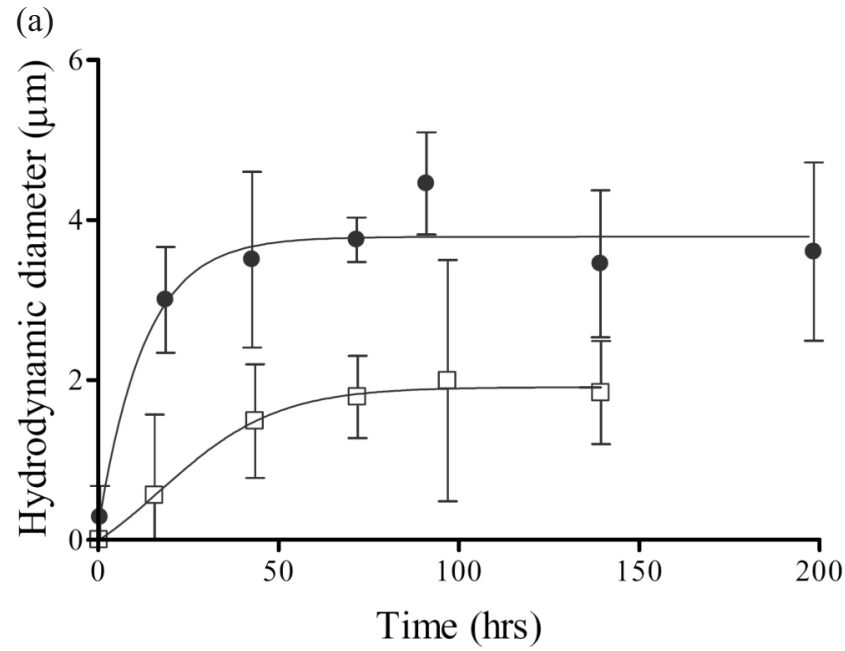

(b)

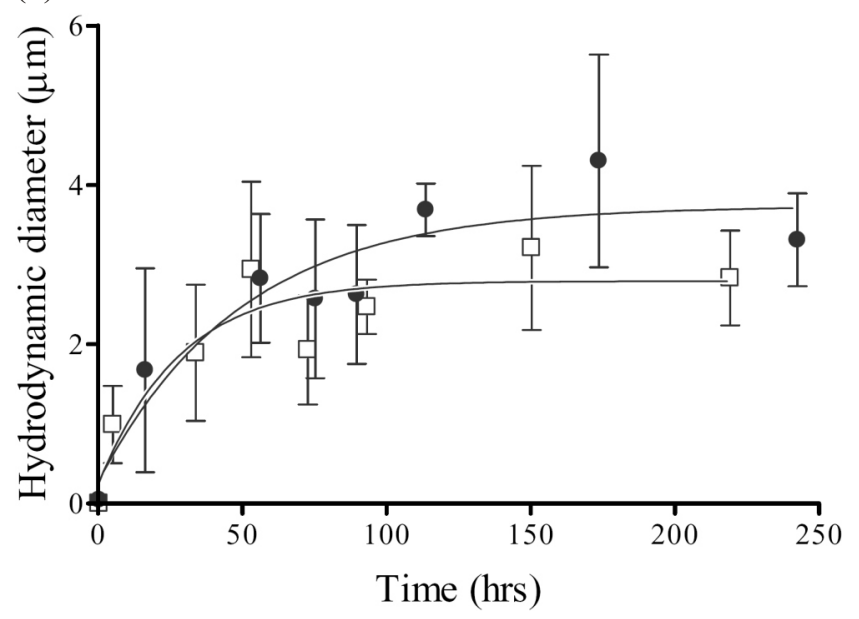

(c)

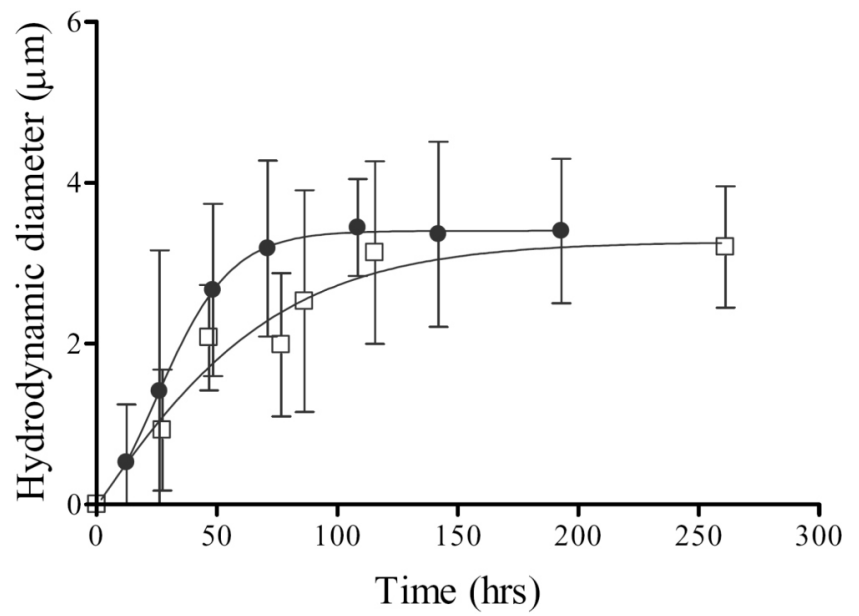

Fig. 1. Spontaneous assembly of exopolymers from phytoplankton in ASW. (a) EPS from Emiliania huxleyi; (b) EPS from Skeletonema costatum; (c) EPS from Synechococcus. Filled circles: ASW with $\mathrm{Ca}^{2+}$; Squares: $\mathrm{Ca}^{2+}$-free ASW. three EPS samples (Table 1). The results demonstrate that EPS from different phytoplankton species might exhibit different mechanisms of assembly depending upon their chemical compositions. The variations of the size measurements with DLS (Figs. 1a - c) are similar to our previous studies with DOC polymers and EPS from Sagittula stellata (Chin et al. 1998; Ding et al. 2008).

\subsection{Fluorescence Enhancement of Nile-Red by Exopolymers from Phytoplankton}

Our self-assembly observations suggest that hydrophobic interactions might play a significant role in the formation of EPS microgels and are consistent with previous reports on the chemical composition of EPS from Emiliania huxleyi, Synechococcus, and Skeletonema costatum (Hung et al. 2005; Alvarado Quiroz et al. 2006). EPS polymers from marine organisms are polysaccharide-rich, containing uronic acids and proteins, but their chemical composition can vary with nutrient and growth conditions (Bhaskar and Bhosle 2005). As might be inferred, slight changes of their composition could affect their physico-chemical properties, e.g., biosurfactant and emulsifying properties. Hence, their role and fate in biogeochemical cycles is largely unexplored (Wotton 2004; Bhaskar and Bhosle 2005). The major components of these EPS samples are carbohydrates, making up to $50 \%$ of the total carbon (Table 1). Although the acidic groups in these EPS are mainly carboxylate, sulphate, and phosphate, they also contain around $2-8 \%$ proteins, rendering them with sufficient hydrophobic domains (Alvarado Quiroz et al. 2006).

Nonetheless, direct evidence of the presence of hydrophobic domains in these EPS polymers that could complement and further support the idea that hydrophobic crosslinking could stabilize the formation of EPS microgels is still missing. We used Nile-red, a widely used fluorescent probe specific for hydrophobic domains, to detect the existence of hydrophobic regions in EPS from Emiliania huxleyi, Skeletonema costatum, and Synechococcus (Fig. 2). Fluorescence spectra of Nile-red showed a very weak signal at maximum emission wavelength $633 \mathrm{~nm}$ in polar ASW solvent with excitation wavelength $568 \mathrm{~nm}$. When we added $100 \mu \mathrm{g} \mathrm{L}^{-1}$ EPS from these phytoplanktons into the seawater samples labeled with Nile-red, the fluorescence signal was enhanced $\sim 15 \%$ (Fig. 2). The observed fluorescence increase suggests that hydrophobic domains are present in these samples. This outcome is consistent with previous reports of EPS chemical composition in these phytoplankton species (Hung et al. 2005; Alvarado Quiroz et al. 2006) and together with our measurements of self-assembly kinetics offer strong support of the idea that hydrophobic interactions play a significant role in the self-assembly of EPS microgels. A similar hydrophobic driven assembly has also been confirmed in marine baterial EPS (Sagittula stellata) (Ding et al. 2008). 

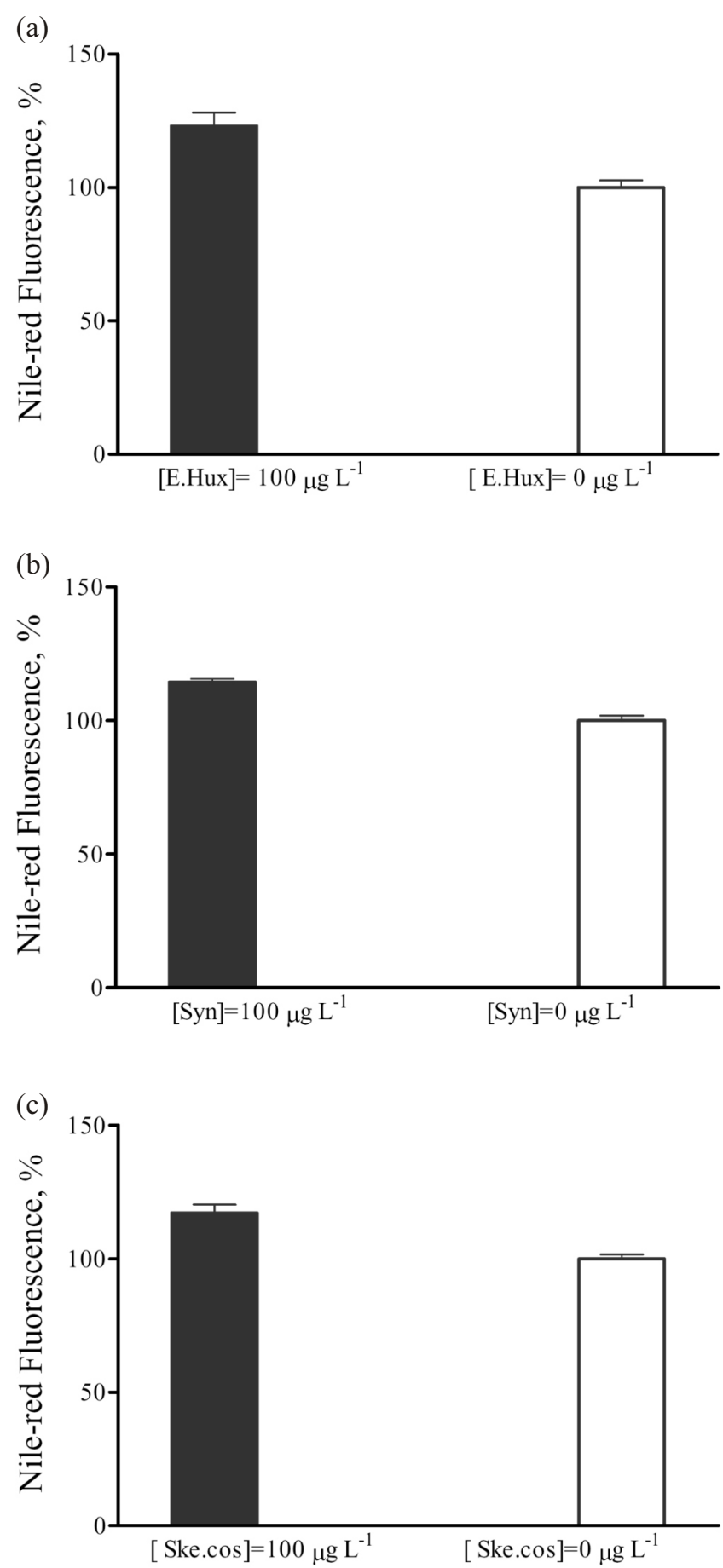

Fig. 2. The detection of hydrophobic domains with Nile-red. Nile-red is a fluorescent dye specific for hydrophobic regions $(\mathrm{Ex} / \mathrm{Em}=568 / 633 \mathrm{~nm})$. In the ASW, Nile-red emitted a very weak fluorescence signal. With the addition of $100 \mu \mathrm{g} \mathrm{L}^{-1} \mathrm{EPS}$, the fluorescence intensity was enhanced by $\sim 15 \%$ ( $\mathrm{p}^{*}<0.001$ ). (a) Emiliania huxleyi; (b) Synechococcus; (c) Skeletonema costatum.

\section{CONCLUSION}

Our previous work indicated that microgels resulting from the self-assembly of DOC contain a tangled topology stabilized mainly by electrostatic interactions resulting from $\mathrm{Ca}^{2+}$ bonds (Chin et al. 1998; Verdugo et al. 2004, 2008). Evidence that hydrophobic interaction could also be at play in the self-assembly of marine biopolymers just as exopolymers from the marine bacterium Sagittula stellata can, at nanomolar concentrations, induce DOC croslinking via hydrophobic interactions (Ding et al. 2008). The results presented here show that EPS from Emiliania huxleyi, Skeletonema costatum, and Synechococcus can also self-assemble forming microcopic gels. Consistent with the amphypathic nature EPS from these phytoplankton species (Alvarado Quiroz et al. 2006), our data suggest that both electrostatic bonding and hydrophobic interactions might play a role in phytoplankton EPS self-assembly. The concentrations of EPS used in our experiments are similar or lower than the concentrations of EPS found during phytoplankton blooms suggesting that this self-assembly process could take place in seawater and might strongly contribute to the formation of hot spots of high bacterial substrate concentration increasing the susceptibility of this important marine carbon stock to metabolic remineralization (Fogg 1983; Baines and Pace 1991; Verdugo et al. 2004).

Acknowledgements This work was supported by grant 0120579 from the Biocomplexity Program of the National Science Foundation, Division of Bioengineering and Environmental Sciences to P. Verdugo; and NSF grants BES0210865 and OCE-0351559 to P. H. Santschi and C. C. Hung; W. C. Chin and C. C. Hung were also supported by grants from UC Pacific Rim Research and GRC Program. This research project was conducted at P. V. laboratory, University of Washington Friday Harbor Laboratories as part of Yong-Xue Ding's Ph.D. dissertation at Florida State University.

\section{REFERENCES}

Alvarado Quiroz, N. G., C. C. Hung, and P. H. Santschi, 2006: Binding of thorium (IV) to carboxylate, phosphate and sulfate functional groups from marine exopolymeric substances (EPS). Mar. Chem., 100, 337-353, doi: 10.1016/ j.marchem.2005.10.023. [Link]

Baines, S. B. and M. L. Pace, 1991: The production of dissolved organic matter by phytoplankton and its importance to bacteria: Patterns across marine and freshwater systems. Limnol. Oceanogr., 36, 1078-1090.

Bhaskar, P. V. and N. B. Bhosle, 2005: Microbial extracellular polymeric substances in marine biogeochemical processes. Curr. Sci., 88, 45-53.

Blanchard, J. S., 1984: Buffers for enzymes. Methods. Enzymol., 104, 404-414, doi: 10.1016/S0076-6879(84)04107-0. [Link]

Campbell, D., M. J. Eriksson, G. Öquist, P. Gustafsson, and A. K. Clarke, 1998: The cyanobacterium Synechococcus resists UV-B by exchanging photosystem II reaction-center D1 proteins. Proc. Natl. Acad. Sci. USA., 95, 364-369, doi: 
10.1073/pnas.95.1.364. [Link]

Chin, W. C., M. V. Orellana, and P. Verdugo, 1998: Spontaneous assembly of marine dissolved organic matter into polymer gels. Nature, 391, 568-572, doi: 10.1038/35345. [Link]

Chisholm, S. W. 2000: Oceanography: Stirring times in the southern ocean. Nature, 407, 685-687, doi: 10.1038/ 35037696. [Link]

Delille, B., J. Harlay, I. Zondervan, J. Stéphan, L. Chou, R. Wollast, A. V. Borges, M. Frankignoulle, U. Riebesell, and J. P. Gattuso, 2003: Organic and inorganic production by the coccolithophore emiliania Huxleyi under different atmospheric $\mathrm{CO}_{2}$ during a mesocosm experiment. Geophys. Res. Lett., 5, 14704.

Dickinson, E. 2003: Hydrocolloids at interfaces and the influence on the properties of dispersed systems. Food Hydrocol., 17, 25-39, doi: 10.1016/S0268-005X(01) 00120-5. [Link]

Ding, Y. X., W. C. Chin, A. Rodriguez, C. C. Hung, P. H. Santschi, and P. Verdugo, 2008: Dynamics of bacterial exopolymer networks and their role in biofilm and marine microgels formation. Mar. Chem., 112, 11-19.

Doco, T., M. A. O'Neil, and P. Pellerin, 2001: Determination of the neutral and acidic glycosyl-residue compositions of plant polysaccharides by GC-EI-MS analysis of the trimethylsilyl methyl glycoside derivatives. Carbohydr. Polym., 46, 249-259, doi: 10.1016/S0144-8617(00) 00328-3. [Link]

Drebes, G., 1974: Marines Phytoplankton, Eine Auswahl der Helgoländer Planktonalgen (Diatomeen, Peridineen). Georg Thieme Verlag, Stuttgart.

Falkowski, P., R. J. Scholes, E. Boyle, J. Canadell, D. Canfield, J. Elser, N. Gruber, K. Hibbard, P. Högberg, S. Linder, F. T. Mackenzie, B. Moore III, T. Pedersen, Y. Rosenthal, S. Seitzinger, V. Smetacek, and W. Steffen, 2000: The Global carbon cycle: A test of our knowledge of Earth as a system. Science, 290, 291-296, doi: 10.1126/science.290.5490. 291. [Link]

Filisetti-Cozzi, T. M. C. C. and N. C. Carpita, 1991: Measurement of uronic acids without interference from neutral sugars. Anal. Biochem., 197, 157-162, doi: 10.1016/ 0003-2697(91)90372-Z. [Link]

Fogg, G. E., 1983: The ecological significance of extracellular products of phytoplankton photosynthesis. Bot. Marina., 26, 3-14.

Guo, L., C. H. Coleman, and P. H. Santschi, 1994: The distribution of colloidal and dissolved organic carbon in the Gulf of Mexico. Mar. Chem., 45, 105-119, doi: 10.1016/ 0304-4203(94)90095-7. [Link]

Hamel, F. G., R. G. Bennett, and W. C. Duckworth, 1998: Regulation of multicatalytic enzyme activitiy by insulin and the insulin-degrading enzyme. Endocrinology, 139, 40614066, doi: 10.1210/en.139.10.4061. [Link]

Hedges, J. I., 1992: Global biogeochemical cycles: Progress and problems. Mar. Chem., 39, 67-93, doi: 10.1016/
0304-4203(92)90096-S. [Link]

Hedges, J. I. and J. M. Oades, 1997: Comparative organic geochemistries of soils and marine sediments. $\mathrm{Org}$. Geochem., 27, 319-361, doi: 10.1016/S0146-6380(97)00056-9. [Link]

Hung, C. C. and P. H. Santschi, 2005: Composition of exoploymeric substances (EPS) produced by marine microorganisms. American Society of Limnology and Oceanography 2005 Annual Meeting, Salt Lake City, Utah.

Hung, C. C., D. Tang, K. Warnken, and P. H. Santschi, 2001: Distributions of carbohydrates, including uronic acids, in estuarine waters of Galveston Bay. Mar. Chem., 73, $305-$ 318, doi: 10.1016/S0304-4203(00)00114-6. [Link]

Hung, C. C., P. H. Santschi, and J. B. Gillow, 2005: Isolation and characterization of extracellular polysaccharides produced by Pseudomonas fluorescens Biovar II. Carbohydr. Polym., 61, 141-147, doi: 10.1016/j.carbpol.2005.04.008. [Link]

Kushner, S. T., J. Acreman, A. Kerry, G. G. Leppard, M. V. Nermut, and D. J. Kushner, 1992: Extracellular fibril production by freshwater algae and cyanobacteria. Microbiol. Ecol., 23, 53-74, doi: 10.1007/BF00165907. [Link]

Medlin, L. K., H. J. Elwood, S. Stickel, and M. L. Sogin, 1991: Morphological and genetic variation within the diatom Skeletonema costatum (Bacillariophyta): Evidence for a new species, Skeletonema pseudocostatum. J. Phycol., 27, 514-524, doi: 10.1111/j.0022-3646.1991.00514.x. [Link]

Myklestad, S. M., E. Skanoy, and S. Hestamann, 1997: A sensitive and rapid method for analysis of dissolved monoand polysaccharides in seawater. Mar. Chem., 56, 279 286, doi: 10.1016/S0304-4203(96)00074-6. [Link]

Orellana, M. V., Y. Vetter, and P. Verdugo, 2000. The assembly of DOM polymers into POM microgels enhances susceptibility to bacterial degradation. EOS Trans. AGU, 49, 128.

Provencher, S. W., 1982: A constrained regularization method for inverting data represented by linear algebraic or integral equations. Comput. Phys. Commun., 27, 213-227.

Schwehr, K. A., A. Miao, L. Truxal, C. C. Hung, C. Xu, and P. H. Santschi, 2009: Effect of relative hydrophobicity on effectiveness of exopolymeric substances (EPS) as scavenging agents of particle-reactive species from aquatic systems. Manuscript in preparation.

Smith, P. K., R. I. Krohn, G. T. Hermanson, A. K. Mallia, F. H. Gartner, M. D. Provenzano, E. K. Fujimoto, N. M. Goeke, B. J. Olson, and D. C. Klenk, 1985: Measurement of protein using bicinchoninic acid. Anal. Biochem., 150, 76-85, doi: 10.1016/0003-2697(85)90442-7. [Link]

Van Oss, C. J., 1995: Hydrophobicity of biosurfaces - Origin, quantitative determination and interaction energies. Colloids Surf. B., 5, 91-110, doi: 10.1016/0927-7765(95) 01217-7. [Link]

Verdugo, P., A. L. Alldredge, F. Azam, D. L. Kirchman, U. Passow, and P. H. Santschi, 2004: The oceanic gel phase: A bridge in the DOM-POM continuum. Mar. Chem., 92 67-85, doi: 10.1016/j.marchem.2004.06.017. [Link] 
Verdugo, P., M. V. Orellana, W. C. Chin, T. W. Petersen, G. van den Eng, R. Benner, and J. I. Hedges, 2008: Marine biopolymer self-assembly: Implications for carbon cycling in the ocean. Faraday. Discuss., 139, 393-398, doi: 10.1039/ b800149a. [Link]

Wells, M. L., 1998: Marine colloids: A neglected dimension. Nature, 391, 530-531, doi: 10.1038/35248. [Link]

Williams, P. M. and E. R. M. Druffel, 1987: Radiocarbon in dissolved organic matter in the central North Pacific Ocean. Nature, 330, 246-248, doi: 10.1038/330246a0. [Link]
Wotton, R. S., 2004: The ubiquity and many roles of exopolymers (EPS) in aquatic systems. Sci. Mar., 68, 13-21.

Yablon, D. G. and A. M. Schilowitz, 2004: Solvatochromism of nile red in nonpolar solvents. Appl. Spectrosc., 58, 843-847, doi: 10.1366/0003702041389328. [Link]

Zouni, A., H. T. Witt, J. Kern, P. Fromme, N. Krauss, W. Saenger, and P. Orth, 2001: Crystal structure of photosystem II from Synechococcus elongatus at $3.8 \AA$ resolution. Nature, 409, 739-743, doi: 10.1038/35055589. [Link] 